\title{
Transitioning from Practice to Health Care Administration: The Later Years
}

\author{
Frank G. Opelka, MD, FACS, FASCRS ${ }^{1}$ \\ ${ }^{1}$ Quality and Health Policy, American College of Surgeons, \\ Washington, District of Columbia \\ Clin Colon Rectal Surg 2019;32:461-464.
}

\begin{abstract}
Address for correspondence Frank G. Opelka, MD, FACS, FASCRS, Quality and Health Policy, American College of Surgeons, 20 F St NW, Suite 1000, Washington, DC 20001 (e-mail: Fopelka@facs.org).
\end{abstract}

Abstract
Keywords
- health care policy
- dual degrees
- transition from
practice
- MBA

Medicine once was a simple career path for individuals. In the early years of medical education, a person entered medical school, and during that initial exposure to clinical medicine, they would first develop a clinical area toward which they would gravitate and develop their expertise. What naturally followed was to seek further training in that clinical discipline through apprenticeships. As medicine became more complex, these mentorships ultimately evolved into more formal graduate medical education in a residency. The first such residency in America began at Johns Hopkins under Sir William Osler, MD, in the 1890s. These residencies were not more formalized across the country for another half a century.

Upon completion of a residency, individuals entered a lifelong practice for 30 or 40-plus years caring for patients. However, insurance was not readily available and care was limited. Lyndon Johnson changed that when he signed Medicare into law in $1965 .^{1}$ The first beneficiary was the former President Harry S. Truman, whose application was witnessed by President Johnson. With the advent of Medicare came an expansion of care, and after its first decade of influence, medicine began to transform. The call for more science grew. Basic science research in highly focused areas furthered discoveries and pushed treatment in specialty medicine. Expansions in research, new therapies, and new technologies continued to extend the frontiers of care. The results have been astonishing. Patients benefitted greatly. Longevity increased through the advances in care, with many more conditions under treatment than years past. And what ensued fiscally was that the cost of care began to outpace the rest of the U.S. economy.

With all the advances, medicine has seen a tremendous increase in complexity too. The medical sciences consider more than 6,000 known diagnoses and 4,000 medications for treatment. When one considers adding in the advanced technologies, physicians find themselves trained in analytic and mechanistic terms, hoping to achieve effective care, act within defensive medicine, and avoid medical errors. ${ }^{2}$ Care teams began to define care as acute, chronic, acute-onchronic, preventive care, and disease screenings. Patients started living longer with more conditions under treatment, calling for a redesign of primary care and building teams for complex surgical or medical specialty care. Patients no longer found all their care at one clinic with one provider. The sheer volume of services and information surrounding a patient has exponentially increased and is beyond the capacity of a single provider to safely manage for all their patients. According to David M. Eddy, MD, PhD, “The complexity of modern medicine exceeds the inherent limits of the unaided human mind." 3
Issue Theme Surgeon Health; Guest Editor: Jennifer S. Davids, MD, FACS, FASCRS
Copyright (C) 2019 by Thieme Medical Publishers, Inc., 333 Seventh Avenue, New York, NY 10001, USA. Tel: +1(212) 584-4662.
DOI https://doi.org/ 10.1055/s-0039-1693421. ISSN 1531-0043. 


\section{Evolution of the Fee for Service Model}

While care models advanced, the business models of fee for service and insurance vehicles struggled to find alignment with clinical medicine. As the complexity increased, care models shifted along with changes in clinical specialties and who provided the necessary services. The costs under fee for service escalated. A "perfect storm" was developing whereby the rising costs would overwhelm the ability to provide clinical services, and gaps in care would become more evident. Health care economists and insurance experts were seeking ways to enable more care and at the same time constraining the economic impact. Among the many recommendations, the Congressional advisory body known as MedPAC (Medicare Payment Advisory Commission) consisted of federally appointed commissioners who provide recommendations to Congress. The chair, Glenn Hackbarth, published his thinking of ways to contain the runaway costs using bundles as a payment model. ${ }^{4}$ Yet, despite these mounting concerns, fee for service continued as the primary business model.

Within the fee for service environment, others took notice of the commercial business opportunities for more health services. By the 1980s, almost every business sector realized the depth and breadth of health care, and along with these scientific advances, the fiscal opportunities in health care emerged for many more commercial enterprises. Many commercial enterprises sought various points of entry into the health care market to take advantage of the economic opportunity. This has included rehabilitation medicine, the pharmaceutical industry, medical devices, and more. These scientific advances added to care model complexity. At the same time, they added costs to the business models of health care with each additional service, driving the government and the insurance sector to become more than passive purchasers of health insurance. Questions about the value and appropriateness of each additional service started to emerge.

\section{Crisis in Health Care Cost Containment}

By the 1990s, commercial enterprises and the federal and state governments were hit with the reality that the fee for service economic model was unstainable financially. Insurance redesign and government regulations to control costs crept into the business of health care. ${ }^{5}$ Acting out of prudent business and national economic policy, commercial businesses, health care insurers, state and federal governments, and patient advocates moved forward to become active elements of health care policies, insurance benefit design, payment models, and, in rare instances, the actual delivery of care.

Aligning the roaring clinical explosion with the rest of the health care stakeholders would result in the first steps to transform health care into a sustainable, modern care model. Medicine that was once a cottage industry, best exemplified by the television series Marcus Welby, MD, in his family practice office, was about to become a major business sector with large-scale clinical delivery systems and modern business operations. Business analytics and intelligence, clinical performance measurement, digital information, and so forth now have become essential parts of modern clinical delivery systems. Major data enterprises such as Google ${ }^{6}$ and Apple have growing health care divisions, which are rapidly accelerating their role in the health care sector of the American market and elsewhere throughout the world.

\section{The Clinician: Transitioning from Practitioner to Administrator}

When you consider the transformation from a cottage industry to a large, integrated delivery system, you also have to appreciate the major shifts in practice today from the career path from medical school to that 30- to 40-year clinical practice with Dr. Welby. At first, physicians who found themselves in the midst of the transformation had few options except to join the transforming world, try to resist the changes, or retire early. As time advanced, a few physicians began to realize that business meetings and corporate decisions inside medical systems lacked the insight of clinical knowledge and its content and context. Complex clinical decisions and corporate decision trees needed to align. The corporatization of clinical care became a challenge at the bedside to best protect the patient while optimizing the resources. These corporate medical meetings at clinics and hospitals interfaced clinical physicians with business administrators, using physicians as volunteers of their time on working committees to represent the needs of the patients and physicians. Yet, with the addition of clinical leads within the business modeling, the clinical considerations added more complexity to the overall business operations. Questions about priorities of care and constraints in resources are often in conflict.

Business administrators and those in charge of clinical operations themselves have their own language and complexity. Clinical operations, finance, health information technology, compliance, and human resources are just some of the divisions that make up the business architecture of a well-run clinical delivery system. For physicians to position themselves effectively to represent patients and other physicians in business meetings required new skills, which were not part of their traditional medical education. ${ }^{8,9}$ To fill their knowledge gaps, many physicians were self-taught; others sought additional studies in programs such as Masters of Business Administration (MBA).

Armed with more overall knowledge and the ability to contribute more to the business plan, these clinicians became more valuable to the success of the organization. ${ }^{10}$ Their value drew physicians away from clinical activities, and many lost revenue, reducing their compensation. The business enterprises soon realized that to appreciate those physicians who brought the most assistance to the strategic and operational side of the business enterprise would require developing funded positions within the administration. These positions started off with titles such as the chief medical officers, chief academic officers, and hospital directorships, and some progressed to become chief executive officers. It seemed that almost overnight the transition from 
Doctor Marcus Welby, to a chief executive officer, MD, had occurred. In fact, these transitions took many decades.

\section{Rise of the Dual-Degree MDs}

These leadership positions increased in value and with time were not just for those physicians in their "later years." Medical education began to include dual tracks with medical degrees combined with various masters programs as a way to enhance the skills of the new graduating classes. The last few years of the twentieth century saw several changes in combined medical degrees. The AMA (American Medical Association) Wire notes that up to $10 \%$ of graduates have dual degrees, with MD-PhD remaining the most common. ${ }^{11}$ Students had realized the value of MBAs in their future role as physicians beyond clinical care. More focus on health services research, health policy, and health information technology added other masters level areas of interests in masters of public health, masters of medical management, masters of health policy and masters in health informatics. Increasing, the medical and residency graduate classes were studded with dual degrees, MD-MPH, MD-JD, MD-MBA, and so forth.

Truly, the once Marcus Welby, MD, graduate of years passed had transitioned to a new wave of physicians. The lifelong clinical practice of Dr. Welby had migrated to a shorter 10-to 20-year practice, which later transitioned to a clinical administrator or chief executive as the second career. In the modern era, upon completion of medical school or residency, some physicians enter dual track careers, one clinical and one nonclinical. Their clinical practices are limited to a few days per week, and their second track follows an alternative career path such as health care management, informatics, policy-making, education, research, or more. The career tracks available for nonclinical positions have blossomed over time beyond the hospital or clinic to all aspects of health care. Physicians are seen in leading positions in government agencies such as Centers for Medicare \& Medicaid Services, Agency for Healthcare Research and Quality, U.S. Food and Drug Administration, Centers for Disease Control and Prevention, U.S. Department of Veterans Affairs, and U.S. Department of Defense; state government; and local public health. Insurers have several medical directors nationally, regionally, and in key clinical service lines. Medical schools often have clinically retired physicians join their faculty as volunteers or compensated teachers. Pharma and the medical device manufacturers cannot do without experienced experts for content and the clinical context of their products. The emerging fields of health information technology, clinical analytics, artificial intelligence, and deep learning are just beginning to explode.

\section{Career Transitions and Alternative Pathways in Medicine}

When is the right time or at what age should a physician begin to consider or plan a transition? Physicians are making clinical and nonclinical career moves at every age. Some are coming out of medical school, whereas others begin in their midsixties as a second career, planning a 10 -year run. The right time is personal. Some individuals wish to complete a primary residency first. Others have clinical burnout after a decade in practice and want a change. ${ }^{12}$ Some are willing to start alternative, nonclinical paths younger before they would face lifestyle changes from pay cuts. Others are willing to shift midcareer, even if it means a reduction in their compensation. Some are willing to leap into a new career, whereas others want to dip a toe in the water and test their effectiveness and personal satisfaction before making a full commitment. What is important is that the individual recognizes that there are many points of entry. They will need to pick the one that suits them and the one that presents itself, even when they are not perfectly ready to jump from one career path to another. The right opportunity may come along at the wrong time, and the physician will have to accept a path that includes an aggressive call for education and growth while on the job. No one is ever fully prepared. Each position is unique and is shaped by the individual within it as well as the organization that surrounds it. The position will not meet you where you are. It will ask that you meet the position at its launch point, taking the lead and moving forward.

For those physicians who are mid- or late career in transition, the next phase of career planning is influenced by a host of factors, not the least of which related to their retirement planning. Retirement planners are important consultants in the human resource department or they may be external experts who can assist you in assessing your personal and financial readiness for retirement. Part of the personal assessment includes a review of your sense of purpose, your job characteristics, your health, and fiscal soundness for retirement goals. Many physicians elect to reduce their practice and transition off the hospital-based services or on-call schedules. Others may elect to volunteer time in educational programs for aspiring, young physicians. Others may transition to assume a role in the administration. All of these transition options are worthy and noble contributions to the medical industry. Some represent a givingback after years of service. Most physicians who elect positions within these transitions that are best suited to their personal interests find some of their greatest rewards in these transition years. Their stories include volunteering as a patient coach to help end of life patients face their decision, teaching clinical examination to nurses and medical students in their early years, or consulting with clinical services on quality, safety, physician burden, or clinical redesign. The lists of options are endless.

\section{Final Considerations}

It is important to recognize that age is just a number and that there is no standard age for retirement. Ultimately, the decision is made by the individual and his/her affiliated institution(s). Factors such as stamina, fine motor skills, and cognitive function decrease over time. Skill assessments can determine attention span memory and other cognitive testing. Other alternatives are to step away from complex 
procedures and limit clinical practice to less strenuous and less complex procedures.

Institutions and clinical practices should plan the final transitions. It is important to recognize the contributions and cumulative wisdom of a senior surgeon. These are valued and should be appreciated. Some of these transitions can include focusing on office-based activities, medical review cases, junior medical staff mentoring, and student education. Lastly, it is important to consider that abrupt transitions from a busy practice are unrealistically disruptive to everyone. Patients, nurses, and other staff all need time to transition a retiring surgeon. A well-planned retirement with a thoughtful exit will create a memorable transition and continue to promote the personal relationships everyone cherishes.

\section{Conflict of Interest}

None.

\section{References}

1 Centers for Medicare \& Medicaid Services. https://www.cms.gov/ About-CMS/Agency-information/History/. Accessed March 18, 2018
2 Kondro W. Medical errors increasing because of complexity of care and breakdown in doctor-patient relationship, physician consultant says. CMAJ 2010;182(13):E645-E646

3 Eddy D. Focus: Evidence-based Medicine. http://kpcmi.org/files/ ebm.pdf. Accessed March 11, 2018

4 Hackbarth G, Reischauer R, Mutti A. Collective accountability for medical care-toward bundled Medicare payments. N Engl J Med 2008;359(01):3-5

5 Schroeder SA, Frist W; National Commission on Physician Payment Reform. Phasing out fee-for-service payment. N Engl J Med 2013;368(21):2029-2032

6 Verily Life Sciences. https://verily.com/. Accessed March 17, 2018

7 Apple Inc. https://www.apple.com/ios/health/. Accessed March 11,2018

8 Mintz LJ, Stoller JK. A systematic review of physician leadership and emotional intelligence. J Grad Med Educ 2014;6(01):21-31

9 Chaudry J, Jain A, McKenzie S, Schwartz RW. Physician leadership: the competencies of change. J Surg Educ 2008;65(03):213-220

10 Falcone RE, Satiani B. Physician as hospital chief executive officer. Vasc Endovascular Surg 2008;42(01):88-94

11 Murphy B. Considering a dual degree? Those who did it share the pros, cons. AMA Wire. Sept 2017. https://wire.ama-assn.org/ education/considering-dual-degree-those-who-did-it-sharepros-cons. Accessed March 3, 2018

12 Sinsky CA, Dyrbye LN, West CP, Satele D, Tutty M, Shanafelt TD. Professional satisfaction and the career plans of US physicians. Mayo Clin Proc 2017;92(11):1625-1635 